\title{
'We've Got Some Underground Business Selling Junk Food': Qualitative Evidence of the Unintended Effects of English School Food Policies
}

1. Adam Fletcher

1. Cardiff University, $U K$

2. Farah Jamal

1. University of East London, $U K$

3. Natasha Fitzgerald-Yau

4. Chris Bonell

1. University College London, $U K$

1. University of Oxford, $U K$

1. Adam Fletcher, Cardiff University School of Social Sciences, Glamorgan Building, King Edward VII Avenue, Cardiff CF10 3WT, UK. Email: fletchera@cardiff.ac.uk

\section{Next Section}

\section{Abstract}

Drawing on two qualitative studies, we report evidence of pervasive black markets in confectionery, 'junk' food and energy drinks in English secondary schools. Data were collected at six schools through focus groups and interviews with students $(n=149)$ and staff $(n=36)$, and direct observations. Supermarkets, new technologies and teachers' narrow focus on attainment have enabled these 'underground businesses' to emerge following increased state regulation of school food and drink provision. These activities represent a new form of counter-school resistance to institutional constraints within the context of enduring, although less visible, class-based stratification in British secondary schools. These black markets also appear to be partly driven by the unsafe and unsociable nature of school canteens, which was a recurring theme across all schools. These findings highlight how new school food 'bans' ignore the complex, ecological drivers of poor diet in youth and the potential for iatrogenic effects which exacerbate health inequalities.

\section{Introduction}

Obesity increased rapidly in high-income countries during the latter part of the 20th century (Strauss and Pollack, 2001). In 2009, 31 per cent of boys and 28 per cent of girls aged two to 15 in England were overweight or obese (Department of Health, 2010). Rates are similar in Scotland and even higher in Wales (Bromley et al., 2011; Welsh Government, 2010). It is predicted that by 2025, 14 per cent of the British population aged under 20 will be clinically obese (McPherson et al., 2007) and health inequalities due to obesity will continue to increase (Stamatakis et al., 2010). In addition to the long-term health risks, obesity during childhood and youth is associated with major adolescent health problems such as type-2 diabetes and depression. Being overweight during youth is also associated with a range of adverse psychosocial outcomes including lower self-esteem and quality of life (Griffiths et al., 2010). 
These trends have been described as a health and economic 'time bomb' (Department of Health, 2003), which has prompted greater emphasis on early intervention and obesity prevention in the UK focused on children, families and schools (Department of Health, 2008). Following Jamie Oliver's high-profile campaign to improve British school lunches, the school food environment in particular has become an issue of major public interest and political importance (Morgan and Sonnino, 2008). Since 2009, all state 'maintained' schools in England - funded by central government via local authorities - have been subject to new statutory nutritional standards, which restrict the sale of less healthy products (such as biscuits and chips) and completely prohibit the sale of chocolate, other confectionery and sweetened drinks (House of Commons, 2008). This focus on addressing school food provision is supported by the World Health Organization's Global Nutrition-Friendly School Initiative and such environmental approaches have been pronounced as a 'common sense cure' to obesity (Ebbeling et al., 2002).

However, the evidence to support the effectiveness of greater restrictions on school food is extremely limited, with no reports of reductions in students' body mass index (BMI) due to such policies (Jamie and Lock, 2009; Larson and Story, 2009; Van Cauwenbergh et al., 2010). In this article, we present evidence that such policies may have harmful unintended consequences. To unravel and theorise the process via which these unintended effects may occur, we draw on Giddens' notion of 'structuration' as an over-arching theoretical framework, and situate Paul Willis' $(1977,1990)$ concepts of 'counter-school' cultural resistance and youth 'proto-communities' within this, to explore the dynamics of agency and structure in this context of greater regulation of secondary school food provision in England.

Giddens' (1984) theory of structuration is instructive for understanding that, while social structures are constructed through human agency, agency is itself both enabled and constrained by these structures within which individuals assess and make their choices; in turn, actively shaping and reconstituting social structures. Young people's health-related behaviours are one example of this structuration in action. For example, heavy alcohol and drug use is both a cause and a consequence of social exclusion through which wider inequalities are reproduced (Fletcher et al., 2009; Pavis and Cunningham-Burley, 1999). The formation of students' dietary behaviours can also only be fully understood within this dynamic, structural context (Moore et al., 2013; Winson, 2008). Without recognising this duality of structure and agency, we may ignore the potential for new social interventions and policies to have harmful effects as people respond actively but in unexpected ways (e.g. Walker, 2007).

Willis' (1977) classic ethnographic study of the working-class 'lads' at a secondary school in the West Midlands (England) illustrated not only how students' identities and actions emerged in opposition to secondary schools' institutional features, but also how their counterschool cultural resistance both reflected and reinforced existing structures of inequality. Although criticised for under-estimating the plurality of different cultural responses among working-class pupils (Brown, 1987), this concept of counter-school cultural resistance illustrates not only the duality of agency and structure in shaping behaviour but also how specific institutional rules and students' cultural and material resources simultaneously enable and constrain this process (Giddens, 1984). Willis' (1977) study formed part of a wider body of work at the Birmingham Centre for Contemporary Cultural Studies on the resourcefulness of young people in resisting those identities ascribed to them by dominant social institutions (Hall and Jefferson, 1976) and in finding new spaces and styles to disrupt the intended 'orderly sequences' of political systems ( 
Re-visiting the issue of youth culture 25 years after his seminal study of working-class counter-school groups, Willis (2003) described the breakdown of traditional class-based social identities as a result of technological change, 'cultural modernisation' and consumerism. Young people's identities have become more reflexive and increasingly based on their common consuming interests (Willis, 2003). However, this is not to say that young people are no longer doing their identity-work collectively. Rather it is the common cultures themselves which have changed: if the 'lads' were proto-workers who identified with the common culture of their local factory and working-class 'estates', then young people are now connected via proto-communities based on their shared styles and interests (Willis, 1990). Nor does this mean that young people's identities are no longer powerfully shaped by their social or economic position, with only the appearance of greater choice, control and opportunity created (Furlong and Cartmel, 2007; Henderson et al., 2007). In fact, this greater invisibility of class merely masks enduring inequalities in Britain, including in students' experiences of, and attainment at, secondary school (Reay, 2006).

Despite long-standing recognition of secondary schools as sites of active, cultural resistance, the responses of students and staff to new school food restrictions have not been examined, and sociological studies of what food means to young people and how they use food remain very rare. Informed by the theoretical framework outlined above, we draw on qualitative data to explore how students and staff view the school food environment and examine how recent policy reforms, including the prohibition of certain products, may have influenced their attitudes and actions. In doing so, this article also responds to the appeal of sociologists of health and illness for empirical public health research which studies the lived experience of 'risk behaviour' (Rhodes, 1997) and recognises the importance of social context and structures in shaping and enabling such behaviour (Scambler, 2011; Williams, 2003).

\section{Methods}

This article draws on qualitative data collected during two research projects undertaken in English secondary schools during the 2011-12 and 2012-13 academic years. The first ('study one') involved a pilot trial and process evaluation to explore the feasibility and acceptability of a new whole-school restorative approach to preventing aggression and bullying in English secondary schools. This was not a study about the school food environment nor students' dietary choices at school per se, although it involved in-depth qualitative research at four schools over the course of one school year (2011-12) during which time the new school food policies and their effects were a consistent theme in student and staff accounts of school life. A separate study ('study two') was conducted between June and October 2012 and involved qualitative case-study research at two secondary schools in London to explore the social dynamics and spatial patterning of girls' health behaviours. In study two, open-ended interviews and focus groups conducted at the first school indicated the presence of extensive black markets in food and, informed by this and the parallel evidence emerging from study one, research in the second school included additional specific questions on the issue of school food to investigate this further.

Taken together, these studies provide rich qualitative data from six secondary schools in London and south-east England, which vary widely in terms of their size, socio-economic profiles and overall Ofsted (English school inspectorate) rating (Table 1). In study one, four matched-pairs of secondary schools were recruited according to their Ofsted-rating of school effectiveness and overall rate of eligibility for free school meals (FSM) prior to random allocation to the intervention group $(n=4)$. In-depth qualitative research was conducted in 
these four schools ('Goldstone Park', 'Railside High', 'Whitehorse Road' and 'Williamson High'). In study two, two all-girls schools in East London ('East Grove' and 'The Crescent') were recruited to explore young women's lived experiences of school in two multi-ethnic, allfemale school institutional environments.

Table 1.

School-level characteristics.

Across the two studies, 129 students took part in focus groups, with a further 20 interviewed individually; and 20 staff took part in focus groups with a further 16 interviewed individually (Table 2). In study one, four focus groups with year-eight students (aged 12-13) and one focus group with staff were undertaken at each school: five to 10 students were purposively recruited and grouped according to their gender and teacher-reported level of school engagement; four to six members of staff, including management, teaching and non-teaching staff, participated. Additional year-eight students $(n=13)$ and a range of school staff $(n=16)$ were also recruited to take part in semi-structured interviews to explore their views of the intervention being piloted and provide further contextual data on the school environment. Focus groups and interviews took place on the school site in private meeting rooms. Two researchers were present during the focus groups and used participatory mapping techniques to promote discussion about the school environment. In study two, students aged 12-17 were recruited via an assistant head teacher: at East Grove, 11 students aged 12-15 participated in a focus group on the school site and seven students aged 16-17 also participated in semistructured interviews held in a private office at the University of East London (UEL) campus; at The Crescent, six students aged 12-15 participated in a focus group on the school site.

Table 2.

Student and staff samples.

Although neither study focused exclusively on school food policies or environments, eating and drinking can be closely linked to experiences of bullying and aggression, and are key health behaviours, thus students in both studies were asked about their experiences of eating at school (e.g. 'where do you eat lunch while at school?', 'what do you like/dislike about your canteen?'). The semi-structured nature of the focus groups and interviews also provided the opportunity to explore students' and staff views about food policies. For example, as young people discussed their involvement in creating new food markets, this was explored further through additional probes (e.g. 'why do you think students buy and sell food at this school?', 'where does this take place?'). Furthermore, in both studies, the use of observations and field notes provided an additional source of data.

All interviews and focus groups were audio-recorded and transcribed verbatim. Using Nvivo software, students' and staff accounts were re-analysed for this article with a specific focus on the school food environment, including: alternative/illicit sources of food and drink; sources of identity, status and bonding relating to food and consumption at school; and, schools' policies, practices and other aspects of school life potentially relevant for understanding the ramifications of the new school food policies. Techniques associated with thematic content analysis and grounded theory were used to analyse the data within this framework (Green and Thorogood, 2004), initially using open/in-vivo coding based on the respondents' own words; with memos being used to record emerging themes and make 
interconnections across schools and studies. Further analyses focused on more detailed coding to interpret the meaning of, and relationships between, the initial themes and patterns within and across schools. Field notes and the maps produced by students in the focus groups in study one were also analysed to provide additional insights into contextual factors which might influence student eating practices. The findings are presented below (all names are pseudonyms). Ethical approval was given by the London School of Hygiene and Tropical Medicine research ethics committee (study one) and the UEL research ethics committee (study two).

\section{Findings}

Student dissatisfaction with school food provision was a recurring theme at all six schools. The issue of prohibitive restrictions and the emphasis on the sale of 'healthy' products was strongly implicated in this. For example: I can get a free school dinner, but I don't want to. I think because it's too healthy. Sometimes you should have a change, but they are just sticking to that and that is why I think more children have pack[ed] lunch and all that. (Female student, 13, The Crescent)

While the new school food standards prohibit the sale of certain products in school, students are still allowed to bring food into school with relatively few restrictions on secondary school packed lunches. Students and staff across all the schools studied described black markets which had developed to meet the demand for confectionery, snack and 'junk' products no longer provided by schools, as well as energy drinks which are totally prohibited from being consumed in schools. For example: We go to Asda, and then buy something cheap and then sell it on [to] make a profit [...] Kitkat, cookies, Chewits [sweets], drinks, doughnuts, anything! (Male, 12, Railside High School) People do sell food in school. You can buy like cookies from Sainsbury for $65 \mathrm{p}$ [ence]. (Female, 15, East Grove) A boy was caught selling with a crate [24 bottles] of Lucozade in school last year [2010-2011]. (Learning support manager, Williamson High School)

One student at Railside explained that he could always 'find a bargain' and 'sell it more expensive' due to the extremely low cost of some supermarket produce. This formula was seen by several students as relatively simple and low risk. For example: You could get a packet [of cookies from Asda] for $50 \mathrm{p}$ [ence]. You'll sell the whole packet for a pound or you'll sell one each for 50 p[ence]. (Female, 13, Railside High School)

Supermarkets therefore essentially act as wholesaler in this illicit supply chain, with students working as local retail agents to provide a service similar to that provided by local convenience stores, with greater accessibility and social contact offsetting the additional economic costs. Prices were generally deemed to be 'reasonable' in the context of heightened demand for sweet snacks and confectionery products, and also compared to the price of food in both the school canteen and some local shops: You can sell things in school, but you are not supposed to [...] Like sweets, chocolate so some people sell food. The prices are so reasonable and they make a profit. They buy it for a pound and sell five for $50 \mathrm{p}$ [ence]. We all know they are making a profit, but it is just like we are at school, we want this food, we are gonna buy it! (Female, 14, East Grove) It's still cheaper than the [local] shops as well 'cos people get it from supermarkets and bring it in. (Male, 13, Railside High School) 
This trade in re-selling snacks and drinks was also facilitated by new mobile technologies such as Blackberry Messenger. One student explained: It happens quite a bit over Blackberry Messenger 'cos I have a Blackberry there's loads and loads of specific messages saying 'Who's selling?', 'I'm selling this', 'I'm selling that'. (Female, 13 Railside High School)

Students often suggested that black markets in products such as supermarket cookies, chocolate bars and energy drinks were an active response to recent legislation and new school policies, particularly the removal of vending machines and prohibition of certain products. For example: We've got some underground business selling junk food. It is just the school can't force you to do anything. You need to be more educated with it. You cannot just force kids, or say 'you can't do this because it is bad for you'. (Female, 15, The Crescent)

However, while new school food legislation may have stimulated this phenomenon, it was apparent that such 'underground businesses' were also simultaneously driven by other features of secondary schooling and societal stratification, which one deputy head teacher described as a 'perfect storm' for junk food. We first describe how students are developing their own low-cost school food environments away from the dangers of the school canteen, enabled by resources such as the proliferation of local supermarkets and new mobile phone technologies described above. Second, we present data to theorise the social value of this illicit trade in food and drink as a new source of identity, 'thrills' and opposition to school, and the enduring relevance of class-based stratification for such counter-school cultures. Finally, we describe accounts regarding how staff either passively or actively support this, and how this is another inadvertent harmful consequence of market-orientated education policies.

\section{Finding a 'Bargain' and 'Calm' outside the Canteen}

Students reported that the school canteen was unpopular not only because of the greater emphasis on 'healthy' products but also because of the high price of this healthy food: They think of health options in the canteen, but because they have recently become so expensive, people would rather go and buy chicken and chips which costs one pound. (Female, 16, East Grove)

Younger students at Railside High School, who were not allowed to leave the school and had set up a local market for trading and distributing snack food, also complained that the few remaining 'nice' options were increasingly expensive and represented poor value for money:

Gavin:Bacon rolls are nice.

Neil:That's expensive though, a little bacon roll like that for a pound [demonstrating the size with his hands].

Gavin:It used to be like $70 \mathrm{p}$ [ence] or something.

Simon:Yeah, it used to be good and then they changed the catering company.

The price of school food thus appeared to be working in parallel with the prohibition of popular products in driving new underground markets in food and drink, especially at schools in poorer areas such as Railside and The Crescent. This illicit trade in prohibited food and drink products was so extensive at these schools that students often made comments such as: 
'There isn't a staff or student who doesn't know about it'. The unpleasant and over-crowded nature of the school canteen also appeared to provide an additional push towards the underground economy at these schools, although this was a cross-cutting theme across all school contexts. Students frequently characterised their school canteens and dining areas as 'noisy', 'crowded' and 'dirty'.

Researchers' observations supported this sentiment and many students appeared largely to avoid the canteen where possible and set up new food environments in the playground, corridors and classrooms. In study one, those students who took part in the focus groups completed a mapping exercise to explore how aggressive behaviours were associated with different areas: 'pushing', 'shoving', 'shouting', 'swearing', 'fighting' (including 'food fights') and 'theft' were commonly mapped onto the school canteen. As well as not feeling safe, several students also expressed frustration at the chaotic, rushed nature of the dinner hall in which they often had insufficient time to eat as a result of fights or other incidents. For example: There was a fight the other day, okay, and it started probably at ten, like five or ten, minutes into lunch [so] they kicked everyone out of the dinner hall but they didn't give us time at the end to get our dinner [...] Like some people didn't even get lunch. (Female, 12, Goldstone Park)

Students frequently reported wanting to escape this environment and spend their lunch-break with friends in their own social spaces. Within these alternative, largely unsupervised, areas such as the playground, corridors, empty classrooms and toilet blocks, students could regain control over their patterns of food consumption, actively creating their own distribution systems and spaces for eating. However, these underground economies also have a deeper cultural context as counter-school food cultures appear to have become another way in which proto-communities of young people can define themselves in opposition to schools.

\section{Eating as Identity-work and New Counter-school Cultures}

It is clear from these new data that food and drink choices now constitute an important source of identity and status for some students. For example, Lucozade and other sports and energy drinks appeared to be an important symbol of masculine, sports-participation for young men. Several students also described that since students are identified in terms of what they eat, lunches provided by parents and having the 'wrong' products could be a source of anxiety and embarrassment. A female student at Railside High School highlighted this during a focus group discussion:

Stacey:There are some people who'll be like, who'll go round, who'll be like [mimicking looking around] 'Oh my God, I've got peanut butter in my sandwich, I must not show them!'

Others:Yeah! [laughing]

Stacey:But some students they'll be seeing her [saying] 'She's the girl that eats peanut butter sandwiches, NOOOO!' [group laughter] - but not as, oh my God, she's that really nice person who gave me five pounds 'cos I had no money. They see her as the girl who eats peanut butter sandwiches!

Not only did food choices appear to constitute an important, and often fraught, part of students' identity-work at school, but engagement in black marketeering could itself fulfil a highly symbolic role as an expression of anti-school resistance. This was especially apparent 
at The Crescent and Railside High School. Both are very large schools with high rates of students from poorer families, eligible for free school lunches. However, despite more students being entitled to free lunches, the underground economies in food appeared most extensive at these schools because they were not simply meeting students' demands for affordable food but also represented a new counter-school response for students from poorer families seeking to resist what they see as prohibitive institutional constraints more generally. Such constraints related not only to the new school food environment but more importantly also to the broader institutional environment at these schools. For example, the 'lads' at Railside who had become heavily involved in this do-it-yourself school lunch trade reported simmering resentment towards being placed in isolation by school staff: It's mostly the people that are like bad in the school, and say are like kicked out of lesson because they got sent parking [isolation], then they just come out in an angry mood [...] they just want to have a laugh. (Male student, 13, Railside High School)

The female students most involved in these new black markets also presented themselves as anti-school students who didn't fit into the academic-orientated ethos of their school and were frustrated that their middle-class teachers were disconnected from the realities of their everyday lives: The teachers don't really care, they don't really care what happens at home, they just care about the grades. (Female, 15, The Crescent) You just sit there [in detention], and like the teachers are [...] having, like, some conversation like a mother's meeting at the back of the hall, like really loud and they're like, 'I bought my new puppy this weekend'. And then, like, as soon as someone does wrong you get an extra half an hour [detention] ... (Female, 13, Railside High School)

These students situated their own and others' actions regarding the establishment of school 'junk' food markets within the context of broader resistance to the many restrictions placed on them at school: They said that we are not allowed mobile phones. I am sure every person here and every person in my form class has a mobile phone on them either switched off or silent. They say that we are not allowed chewing gum, so many kids have chewing gum or bubble gum. If they are going to restrict us and say we are not allowed junk food or crisps or something, obviously, we are just going to do the opposite because that is what teenagers like to do. They don't actually listen to [being] ordered, they just do whatever they want. (Female, 14, The Crescent)

The black market can therefore be seen as an active cultural response to the rules imposed on students at school, particularly at those schools with large numbers of students from poorer households. This may also reflect broader family and community opposition to the dominant middle-class 'healthist' culture imposed within schools (and society more widely). One student explained that her family encouraged her to have a takeaway on Friday: My dad gives me two pound a week, which is sad because I am free school dinners anyway. He just thinks take that two pound for Friday for a takeaway! (Female, 15, The Crescent)

Such cultural opposition to some extent echoes the clash of the middle-class school culture and working-class community and family culture observed by Willis (1977). While such overt class connotations are now less obvious, the alienation and disengagement of workingclass students has been ignored rather than eradicated. Like Willis' 'lads', these new protocommunities of students were smuggling food and drink products into school and illicitly trading them to develop their social identity and to bolster their counter-school and economic capital. For example, the 'football lads' at Railside reported the iconic status being granted to 'super sellers' who were making up to $£ 70$ a day. It was seen as an equally profitable but 
much 'safer' form of underground economic activity than selling drugs, and associated with little or no punishment:

Neil:It's the same thing, it's not selling drugs but it's the same thing.

Mikey:Because you're not allowed to sell drugs.

Neil:The guy's just making a profit out of someone else's product [but with food and drink].

Mikey:And when they [school staff] catch you they just take your stuff that you get [back] at the end of the day.

Disengaged rebellious female students also appeared to see (re)selling food and drink in school as both an opportunity to make a few 'bucks' and as a rare source of excitement at school: [It's] the thrill of it, you know it is always exciting when you have a couple of bucks in your hand and you can spend it on whatever you want and get it from people, it is just more money and more thrill. (Female, 14, The Crescent)

However, while the institutional environment enabled some forms of counter-school opposition, students can only partially penetrate this and the act of resistance ultimately reinforces students' marginal position (Fletcher at al., 2009; Willis, 1997). In this case, the process of 'trading up' food in schools may reproduce existing health inequalities as disengaged anti-school students increase their junk food consumption. For example, one female student explained how her friend could now afford a 'KFC' after selling enough supermarket cookies. Furthermore, these new counter-school food cultures were not universally supported and divisions appeared at The Crescent, where some students characterised others as 'desperate' or 'disgusting' in resisting the school food environment. At Railside, more engaged middle-class, pro-education students and senior school staff also offered narratives portraying such behaviours either as desperate or worthy of pity: People try and make a profit out of like buying a pack of like a pack of five KitKats, Crunchies, Mars bar, bring them to school and then sell them for something like $50 \mathrm{p}$ [ence]. And they make up the worst excuses [like] 'My nan's got a tumour - buy a KitKat!' (Female student, 13, Railside High School) Some people think it's cool to have like a can of KA [carbonated fruit drink] ... 'I've got KA guys!' 'Fuck - no way!' [mocking excitement]. (Female student, 13, Railside High School) It's the poor ones that do it for money. It's the parents that probably send them with the stuff. (Senior teacher, Railside High School)

This exemplifies the 'hidden' tensions and injuries of class which still stalk secondary schools (Reay, 2006), as working-class identities are less culturally visible but the stratification, alienation and restraint of these poorer students persists.

\section{Marketisation Harms: Hiding Problems and Counter-school Lunchtime Supervisors}

These data also provided further evidence regarding the harmful health effects of marketorientated education models (Bonell et al., 2012; Fletcher et al., 2010). An over-arching theme across both studies was that school staff were narrowly focused on their 'core work' of managing their own classrooms to achieve school-level and individual targets regarding student attainment, and that they increasingly withdrew from pastoral and whole-school disciplinary roles. Staff were thus reluctant to 'get involved' in enforcing the new statutory 
bans, which were seen as beyond the scope of such 'core work', and students themselves recognised this: I actually think they do know, but they don't want to get involved. (Female, 17, East Grove) We're not allowed to actually sell things inside school yet Rosie was selling it around in PE with teachers around. (Female, 13, Railside High School)

The head teacher at Railside, which is rated as an 'outstanding' school by Ofsted inspectors, openly acknowledged that neither school inspections nor 'league tables' focus on healthy eating and as such it was a low priority. The advent of parental 'choice' (in theory at least) and greater competition between schools may also encourage schools to deny the existence of health and social problems among their students, and therefore encourage staff to deny rather than address new counter-school black markets in prohibited food and drink. Students reported that while staff were concerned about the school's reputation, in reality they didn't care about new black markets in junk and snack foods: When I go past someone, they are having junk food, it is not like 'health' whatever it says on the [school] website! I don't think it is, because [the teachers] they may want to paint a picture like that and they want to show it [but] I don't think so. (Female, 15, The Crescent)

Furthermore, as they focused on maximising academic attainment, school managers and teachers admitted they are rarely present in the school canteen and other communal areas at lunchtime. A senior member of staff at Williamson High School also described the increasing rate of staff turnover during her career as the 'premiership football manager syndrome', with few staff remaining in post for long periods of time, which also further limited teachers' and managers' involvement in the school community 'beyond the classroom'. To paraphrase Jane Jacobs (1961), there were insufficient eyes on the school at break and lunchtimes at these schools. One teacher felt that staff were now rooted in their own rooms: I'm in my class at breaks $[\ldots]$ it's an on-going project [by the school management] not to have a staff room. A lot of other teachers used to, you know, to go down for break and lunchtime in the staffroom and be with other teachers and move [around]. Not any more. (Teacher, Railside School)

Students reported how temporary lunchtime supervisors were left out-numbered and reluctant to intervene: They usually have one lady there. At lunchtime it is her against a group of like 150 teenagers running round and round and she can't control them [...] The power that she has is very little. (Female, 17, East Grove)

At one school, students even reported that these lunchtime supervisors would themselves capitalise on the demand for popular snack products such as crisps no longer sold in school. A student explained: The dinner ladies started coming in and selling crisps and stuff [...] I bought crisps, yeah, they came and they were selling for something like $20 \mathrm{p}$ [ence] a crisp packet [from] a Walker's packet, a big [multi]packet and they were selling the little crisps out to anyone who wanted it. (Female, 14, The Crescent)

This example of the external school lunch supervisors resonates with Devine's (1995) research on private security guards deployed in American high schools, who came from the same deprived communities as students, had little stake in the school, and either failed to prevent, or actively engaged in, drug dealing or sexual harassment on school premises once teachers were no longer present.

\section{Discussion}


These data suggest that simple, supposedly 'common sense' solutions to poor diet and obesity are insufficient and can even have unintended, potentially harmful, consequences. Although legislation focused on regulation and the control of certain health-related behaviours can be effective (e.g. banning smoking in public spaces), outright prohibition often fuels new underground economies and potentially greater health harms (Edwards, 2004). The National Prohibition Act in the USA in the 1920s, which was designed to reduce health harms by banning the production and sale of alcohol, simultaneously created new problems as prohibition was resisted via black marketeering. Underground economies are also common in times of austerity and rationing, where they are an important distribution channel for illegal goods and circumventing retail controls (Neuwirth, 2011; Roodhouse, 2013). While dissatisfaction with school food is far from new and illicit food markets may have always existed in some schools, recent legislative changes appear to have intensified such underground activity. It is notable that other qualitative studies of anti-school peer groups and school food undertaken in England prior to more restrictive food standards do not report such black markets operating (e.g. Lloyd et al., 2009; Wills et al., 2005), and many students and staff we spoke to attributed the rise of black markets (at least in part) to the new school food legislation.

Even if the new legislation has provided additional impetus for students to set up such 'underground businesses', other environmental and structural drivers are also at play. As with teenage motor vehicle accidents (Allen and Brown, 2008), policy makers may have inadvertently created another 'perfect storm' for adolescent health risk. In this case, the perceived high cost and poor value of 'healthy' food (particularly for students from poorer communities) provided in rushed, over-crowded canteen environments, in the context of stayon-site lunchtime policies, and in the absence of staff who have any stake in the school community, drive students to create new food environments. Previous qualitative studies have highlighted similar unpopular features of the school canteen (Pike and Colquhoun, 2009; Wills et al., 2005). The present study also suggests the importance of situating these problems in the context of market-orientated education policies, which encourage staff to focus only on key attainment metrics and hide public health problems. The close proximity of supermarket outlets to some schools also appeared to fuel the underground trade in illicit food. Narrow policy responses, which only focus on restricting choice and prohibiting certain products within schools, ignore these 'ecological' drivers of poor diet and obesity (Lang and Rayner, 2012; Moore et al., 2013).

While the cultural meaning of food has long been recognised by anthropologists (e.g. Douglas, 1975; Levi-Strauss, 1969), limited attention has been given to the meaning and representation of food in sociological studies of youth cultures and transitions (Wills, 2005). This study suggests the centrality of such consumption practices for identity construction and bonding at school, including as a source of opposition to school among proto-communities of students coalescing around more fluid, and thus less predictable, sources of common culture (Willis, 1990). Structuration is a useful lens when exploring such unanticipated consequences of well-intentioned policies. This is structuration in action: school environments are not static, externally controlled structures; local agents have their own resources and the capacity to act creatively to reconstitute this environment. Enforcing unpopular, mono-factorial public health responses within a highly complex ecological system ignores individuals' transformative power. This study also supports the view that consumer culture and productbranding specifically enable these new youth 'tribes' to create new forms of contemporary sociality (Maffesoli, 1996; Milner, 2004) and that such 'post heroic' subcultures are often highly interactive with capitalist enterprise (larke, 2003). 
However, this should not obscure how enduring class-based stratification continues to powerfully shape both schooling and youth cultures: new proto-communities coalescing around more commercially orientated, shared styles and tastes may be less predictable but their identity and rebellion remains a product of jagged structural divisions within British society. Diane Reay's (2006) working-class 'zombie' is not only stalking the classrooms of English schools but also resisting the new 'healthist' food culture. The young black marketeers described here are Willis' (2003) foot soldiers of modernity, actively enabled by new technologies, supermarket economics and market-orientated educational policies, still adopting oppositional identities based on their shared patterns of consumption, and still undermined as 'disgusting' and 'desperate' by pro-education middle-class students and staff. This represents an extension of 'chav' discourses into school food and further vilification of working-class students based on their consumption (Hayward and Yar, 2006; Jones, 2011). Such middle-class practices add up to a powerful collective class action in the field of education (Reay, 1998).

These qualitative data have been valuable but this research is not without its limitations. The data were collected at only six schools and our data may not reflect the experiences and perspectives of all students, even within our sample of schools. Neither study specifically aimed to explore school food policies a priori. Nonetheless, the open-ended approach to investigating various aspects of the school environment exposed that underground food markets exist across the schools participating in this research. That this was apparent despite neither study looking specifically for this is perhaps evidence of the extent of these problems. Further evaluation is urgently required as bans appear to be subverted and cannot be assumed to be effective; including research to explore the views of school staff in more depth and how the emergence of black markets may vary in different contexts. Policy makers could also seize the natural experiment currently in operation in England by comparing students' diet and BMI at schools with 'academy' status, which are not subject to the same statutory restrictions, and state-maintained schools.

\section{Conclusion: A New Nation of Shopkeepers?}

Britain has long been considered a 'nation of shopkeepers' - Adam Smith used the term in The Wealth of Nations in 1776 - and we may now be rearing a new nation of shopkeepers in English secondary schools. Schools have long been a place of working-class resistance to state intervention and these underground distribution systems for food and drink represent a further example of counter-school resistance in the face of both greater restrictions on school food and also the persistently constraining nature of wider school institutional features. From a public health perspective, these findings are alarming as they suggest young people still have easy access (perhaps easier access than ever because of the proliferation of supermarket outlets) to 'junk' food, calorific snack products and sweetened drinks while in school. New school food standards introduced in 2009 may therefore be another case of a well-meaning policy with unintended harmful consequences, potentially exacerbating health inequalities if any harmful effects are concentrated in the most disadvantaged schools. A more appropriate starting point for improving diet through schools would be more a democratic intervention to give young people a greater voice and therefore the opportunity to shape the school food environment more legitimately, rather than increasing restrictions until they set up their own underground convenience stores.

\section{Article Notes}


Funding:

This research was funded by the National Institute of Health Research (study one) and the University of East London Early Career Researcher Accelerator Fund (study two). We would also like to thank the anonymous reviewers for their extremely helpful comments and suggestions.

Adam Fletcher is a Senior Lecturer in the Cardiff School of Social Sciences. He joined the School in 2012 having previously worked at the London School of Hygiene and Tropical Medicine and the Institute of Education. His main area of research interest is the social determinants of young people's health, and he has written extensively about the effects of education policies and the school environment on health outcomes.

Farah Jamal is a Research Fellow in the Institute of Health and Human Development at the University of East London (UEL). Her research interests include the social and cultural determinants of adolescent health and health inequalities. While at UEL she has worked on a National Institute of Health Research (NIHR) project examining the effects of schools and school-environment interventions on young people's health.

Natasha Fitzgerald-Yau is a Research Assistant at the Institute of Child Health at University College London (UCL). She previously worked at the Anna Freud Centre at UCL on the national evaluation of the Targeted Mental Health in Schools (TaMHS) programme for the Department of Education.

Chris Bonell is Professor of Sociology and Social Intervention at the University of Oxford. He joined the Department of Social Policy and Intervention at Oxford in 2011 having previously worked at the London School of Hygiene and Tropical Medicine, the Institute of Education, and the Cabinet Office's Social Exclusion Unit. His main area of research interest is the development and evaluation of social interventions and policies to promote the health of young people, particularly interventions which address the school environment. He has published extensively in this area and has directed major evaluation projects for the MRC, NIHR and the Department of Health in England.

\section{References}

Allen JP, Brown BB (2008) Adolescents, peers and motor vehicles: The perfect storm. American Journal of Preventive Medicine 35(3): S289-S293.

Bonell C, Fletcher A, McKee M, Sorhaindo A, Wells H (2012) How market-oriented education policies might influence young people's health: Development of a logic-model from qualitative case-studies in English secondary-schools. Journal of Epidemiology and Community Health 66: e24.

Bromley C, Corbett J, Day J, et al . (2011) The Scottish Health Survey 2010. Edinburgh: Scottish Centre for Social Research.

Brown P (1987) Schooling Ordinary Kids: Inequality, Unemployment and the New Vocationalism. London: Tavistock. 
Muggleton D, Weinzierl R, Clarke D (2003) The death and life of punk: The last subculture. In: Muggleton D, Weinzierl R (eds) The Post-Subcultures Reader. Oxford: Berg, 223-38.

Department of Health (2003) Health Check: On the State of the Public Health. Annual Report of the Chief Medical Officer 2002. London: Stationery Office.

Department of Health (2008) Healthy Weight, Healthy Lives: A Cross-government Strategy for England. London: Department of Health/Department of Children, Schools and Families.

Department of Health (2010) Health Survey for England, 2009. London: NHS Information Centre.

Devine J (1995) Can metal detectors replace the panopticon? Cultural Anthropology 10: 171-95.

Douglas M (1975) Implicit Meanings: Essays in Anthropology. London: Routledge.

Ebbeling CB, Pawlak DB, Ludwig DS (2002) Childhood obesity: Public-health crisis, common sense cure. The Lancet 360(9331): 473-82.

Edwards G (2004) Matters of Substance: A Short History of Drugs. London: Picador.

Fletcher A, Bonell C, Rhodes T (2009) New counter-school cultures: Female students' drug use at a high-achieving secondary school. British Journal of Sociology of Education 30(5): 549-62.

Fletcher A, Bonell C, Sorhaindo (2010) 'We don't have no drugs education': The myth of universal drugs education in English secondary schools? International Journal of Drug Policy 21(6): 452-8.

Furlong A, Cartmel F (2007) Young People and Social Change: New Perspectives. Milton Keynes: Open University Press.

Giddens A (1984) The Constitution of Society. Cambridge: Polity Press.

Green J, Thorogood N (2004) Qualitative Methods for Health Research. London: Sage.

Griffiths LJ, Parson TJ, Hill AJ (2010) Self-esteem and quality of life in obese children and adolescents: A systematic review. International Journal of Pediatric Obesity 5(4): 282-304.

Hall S, Jefferson T (1976) Resistance through Rituals: Youth Subcultures in Post-war Britain. London: Routledge.

Hayward K, Yar M (2006) The 'chav' phenomenon: Consumption, media and the construction of a new underclass. Crime, Media and Culture 2(1): 9-28.

Hebdige D (1979) Subculture: The Meaning of Style. London: Methuen.

Henderson S, Holland J, McGrellis S, Sharpe S, Thompson R (2007) Inventing Adulthoods: A Biographical Approach to Youth Transitions. London: Sage. 
House of Commons (2008) The Education (Nutritional Standards and Requirements for School Food) (England) (Amendment) Regulations 2008. Available at:

http://www.legislation.gov.uk

Jacobs J (1961) The Death and Life of Great American Cities. New York: Random House.

Jamie PC, Lock K (2009) Do school based food and nutrition policies improve diet and reduce obesity? Preventive Medicine 48(1): 45-53.

Jones O (2011) Chavs: The Demonization of the Working Class. London: Verso.

Lang T, Rayner G (2012) Ecological public health: The 21st century's big idea? BMJ 345: e5466.

Larson N, Story M (2009) A review of environmental influences on food choices. Annals of Behavioural Medicine 38: 56-73.

Levi-Strauss C (1969) Mythologiques. Vol. 1: The Raw and the Cooked. London: Cape.

Lloyd S, Caraher M, Madelin T (2009) The School Foodshed: Fast Food and Schools. London: Centre for Food Policy, City University.

McPherson K, Marsh T, Brown M (2007) Tackling Obesities: Future Choices - Modelling Future Trends in Obesity and their Impact on Health. London: Government Office for Science.

Maffesoli M (1996) The Time of the Tribes: The Decline of Individualism in Mass Society. London: Sage.

Milner M (2004) Freaks, Geeks, and Cool Kids: American Teenagers, Schools, and the Culture of Consumption. New York: Routledge.

Moore L, De Silva-Sanigorksi A, Moore SN (2013) A socio-ecological perspective on behavioural interventions to influence food choice in schools: Alternative, complementary or synergistic? Public Health Nutrition 16(6): 1000-5.

Morgan KJ, Sonnino R (2008) The School Food Revolution: Public Food and the Challenge of Sustainable Development. Oxford: Earthscan.

Neuwirth R (2011) Stealth of Nations: The Global Rise of the Informal Economy. New York: Pantheon.

Pavis S, Cunningham-Burley S (1999) Male youth street culture: Understanding the context of health-related behaviours. Health Education Research 14: 583-96.

Pike J, Colquhoun D (2009) The relationship between policy and place: The role of school meals in addressing health inequalities. Health Sociology Review 18: 50-60.

Reay D (1998) Class Work: Mothers' Involvement in Children's Schooling. London: University College Press. 
Reay D (2006) The zombie stalking English schools: Social class and educational inequality. British Journal of Educational Studies 54(3): 288-307.

Rhodes T (1997) Risk theory in epidemic times: Sex, drugs and the social organisation of 'risk behaviour'. Sociology of Health \& Illness 19(2): 208-27.

Roodhouse M (2013) Black Market Britain, 1939-1955. Oxford: Oxford University Press.

Scambler G (2011) Health inequalities. Sociology of Health \& Illness 34(1): 130-46.

Smith A (1776) An Inquiry into the Nature and Causes of the Wealth of Nations, 1st edn. London: W. Strahan.

Stamatakis E, Zaninotto P, Falaschetti E, Mindell J, Head J (2010) Time trends in childhood and adolescent obesity in England from 1995 to 2007 and projections of prevalence to 2015. Journal of Epidemiology and Community Health 64(2): 167-74.

Strauss RS, Pollack HA (2001) Epidemic increase in childhood overweight, 1986-1998. Journal of the American Medical Association 286(22): 2845-8.

Van Cauwenberghe E, Maes L, Spittaels H, et al (2010) Effectiveness of school-based interventions in Europe to promote healthy nutrition in children and adolescents: Systematic review of published and 'grey' literature. British Journal of Nutrition 103(6): 781-97.

Walker I (2007) Drivers overtaking cyclists: Objective data on the effects of riding position, helmet use, vehicle type and apparent gender. Accident Analysis \& Prevention 39(2): 41725 .

Welsh Government (2010) Welsh Health Survey 2010. Cardiff: Welsh Government Statistical Directorate.

Williams GH (2003) The determinants of health: Structure, context and agency. Sociology of Health \& Illness 25: 131-54.

Willis P (1977) Learning to Labour: Why Working-class Kids Get Working-class Jobs. Farnborough: Saxon House.

Willis P (1990) Common Culture: Symbolic Work at Play in the Everyday Cultures of the Young. Buckingham: Open University Press.

Willis P (2003) Foot soldiers of modernity: The dialectics of cultural consumption and the 21st-century school. Harvard Education Review 73(3): 390-415.

Wills W (2005) Food and eating practices during the transition from secondary school to new social contexts. Journal of Youth Studies 8(1): 97-110.

Wills W, Backett-Milburn K, Gregory S, Lawton J (2005) The influence of the secondary school setting on the food practices of young teenagers from disadvantaged backgrounds in Scotland. Health Education Research 20: 458-65. 
Winson A (2008) School food environments and the obesity issue: Content; structural determinants, and agency in Canadian high schools. Agriculture and Human Values 25(4): 499-511. 